\title{
Implementasi Accelarated Learning Model untuk Meningkatkan Hasil Belajar Berbasis Video Web
}

\author{
Nurjayadi $^{*}$, Karpen ${ }^{2}$ \\ ${ }^{1.2}$ STMIK Amik Riau \\ "nurjayadi@stmik-amik-riau.ac.id
}

\begin{abstract}
In college, education systems is normally done with conventional lecture which sometimes still has many weaknesses. So it is needed another study model which is tailored to needs on the college to improve learning outcomes. One model of learning was the implementation of an online learning where the learning process will be effective for practice and feedback is integrated with the material given in class. Generally, this research aims to create a web-based video application to support teaching and learning activities at campus STMIK Amik Riau. The specific objectives to be achieved is to improve student learning outcomes and facilitate the lecturer to monitor practicum implementation which is not guided by lecturers to apply Accelarated Learning Model. The study is planned start from planning, system analysis, system design, and program codes to implement the system based on the SDLC (System Development Life Cycle) method. To build this application required a web-based software programming. Expected outcomes of this research is a web video application to support the implementation of the lectures primarily on lab courses in STMIK-AMIK Riau.
\end{abstract}

Keywords: web video, accelarated learning, achievement

\begin{abstract}
Abstrak
Pada perguruan tinggi sistem perkuliahan pada umumnya dilaksanakan dengan kuliah mimbar (konvensional), yang terkadang masih banyak kelemahan. Sehingga perlu model pembelajaran lain disesuaikan dengan kebutuhan di lapangan, untuk meningkatkan hasil belajar. Salah satu model pembelajaran tersebut adalah penerapan pembelajaran secara online. Dimana proses pembelajaran akan berjalan efektif karena latihan dan umpan balik diintegrasikan dengan materi yang diberikan di kelas. Secara umum penelitian ini bertujuan untuk membuat sebuah apliasi web video untuk mendukung kegiatan proses belajar mengajar pada kampus STMIK Amik Riau. Tujuan khusus yang ingin dicapai adalah meningkatkan hasil belajar mahasiswa dan memudahkan pemantauan dosen yang dalam pelaksanaan praktikum tidak di dampingi oleh dosen pengampu guna menerapkan Accelarated Learning Model. Penelitian direncanakan mulai dari perencanaan, analisa system, perancangan system, coding, Implementasi sistem dengan berpedoman pada metoda SDLC (System Development Life Cycle). Untuk membangun aplikasi ini dibutuhkan software aplikasi pemrograman berbasis web. Luaran yang diharapkan dari hasil penelitian ini adalah sebuah aplikasi web video untuk mendukung pelaksanaan perkuliahan terutama pada matakuliah praktikum pada STMIK-AMIK Riau.
\end{abstract}

Kata kunci: web video, accelarated learning, prestasi

\section{Pendahuluan}

Accelerated Learning merupakan dua kata yang digabung menjadi satu, yaitu Accelerated yang berasal dari bahasa inggris yang mempunyai arti dipercepat dan Learning yang mempunyai arti pembelajaran. Jadi, Accelerated Learning dari segi bahasa berarti pembelajaran yang dipercepat [1]. Berkaitan dengan itu, kegiatan pembelajaran dapat berlangsung dengan baik apabila mahasiswa ikut berpartisipasi secara aktif di dalamnya. Belajar bukan merupakan suatu yang terjadi secara alamiah, tetapi hanya akan terjadi dengan kondisi-kondisi tertentu yang dipengaruhi oleh faktor internal, menyangkut kesiapan mahasiswa dan apa yang telah dipelajarinya, dan faktor eksternal, berupa kondisi belajar dan pengelolaan penyajian oleh dosen dengan tujuan untuk memperlancar proses belajar mengajar. Dengan kondisi ini 
maka disamping dosen sebagai salah satu faktor yang menentukan keberhasilan pembelajaran, maka diperlukan alat bantu atau media pengajaran yag tepat agar mahasiswa lebih mudah memahami materi ajar.

Pada kampus STMIK Amik Riau dalam proses pembelajaran terhadap mahasiswa untuk mengikuti proses perkuliahan saat ini sudah semakin bergantung pada teknologi informasi, salah satunya adalah dalam memperoleh bahan ajar perkuliahan. Proses pembelajaran sebatas tatap muka selama jadwal perkuliahan wajib masih belum cukup dalam membantu proses pemahaman pembelajaran mahasiswa secara umum. Wadah komunikasi dalam proses belajar mengajar masih sebatas ruangan kelas, karena waktu yang tersedia dalam proses pembelajaran langsung di kelas dalam 1 SKS kurang dari 50 menit terutama untuk kelas malam. Selain itu media pembelajaran masih lebih didominasi yang bersifat textbook.

Untuk itu dibutuhkan suatu sistem pembelajaran yang dapat memanfaatkan kinerja komputer dan program khusus agar lebih membantu kemudahan dan kelancaran belajar mengajar. Salah satunya adalah dengan adanya sistem pembelajaran online dengan video yang terkomputerisasi secara langsung yang dapat berjalan pada jaringan komputer sehingga aktifitas pembelajaran diluar kelas menjadi lebih efektif guna meningkatkan hasil belajar mahasiswa.

\section{Metoda Penelitian}

Tahapan dalam metode penelitian ini adalah pengembangan sistem dan pengumpulan data serta informasi.

1. Pengembangan sistem

Dalam pengembangan sistem menggunakan SDLC, yaitu dengan menerapkan metodologi waterfall model [2] yaitu dengan tahapan : (a) Tahap Perencanaan. (b) Analisa Sistem, (c) Desain Sistem, (d) Pemrograman, (e) Testing dan (f) Implementasi Sistem.

2. Pengumpulan data
Pada pengumpulan data menggunakan 2 metode yaitu : (a) Wawancara dengan dosen dan mahasiswa untuk mengetahui masalah dan hasil belajar mahasiswa, (b) Pengamatan langsung guna mengetahui gambaran sistem informasi perkuliahan yang sedang berjalan.

Selanjutnya dalam menerapkan metode accelarated learning dibagi menjadi 6 (enam) langkah dasar [3], yaitu :

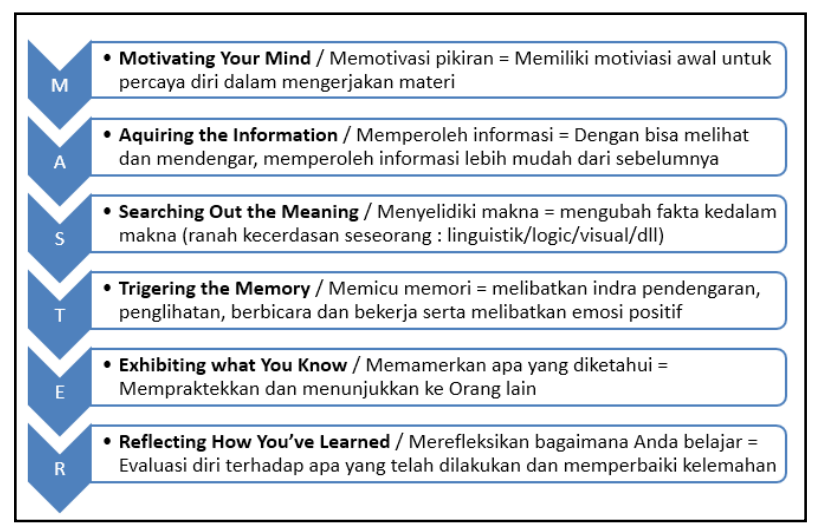

Gambar 1. Langkah Metode Accelarated Learning

\section{Hasil Penelitian}

Hasil dan pembahasan tertuang dari gambaran bagaimana aplikasi digunakan berikut ini.

\subsection{Gambaran Aplikasi}

Gambaran berikut dibuat sebagai interaksi antar pengguna pada sebuah sistem dengan sistemnya sendiri melalui sebuah cerita bagaimana aplikasi digunakan.

\section{a. Hirarki Pengguna}

Terdiri dari tiga aktor dalam interaksi sistem ini, yaitu administrator sebagai pengendali jalannya sistem, dosen, dan mahasiswa. 


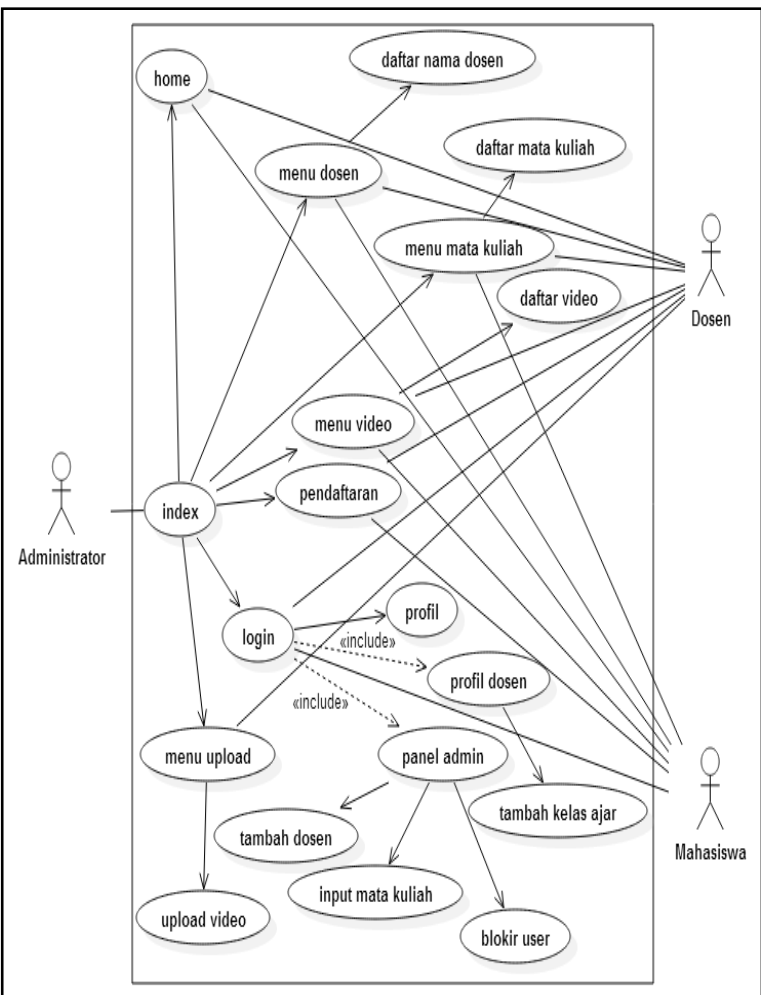

Gambar 2. Hirarki Pengguna

\section{b. Hirarki Program}

Hirarki berikut digambarkan untuk mengetahui arah dari pada aplikasi digunakan oleh user. Sehingga dapat diketahui bahwa user berada pada bagian yang jelas dalam menjalankan aplikasi ini.

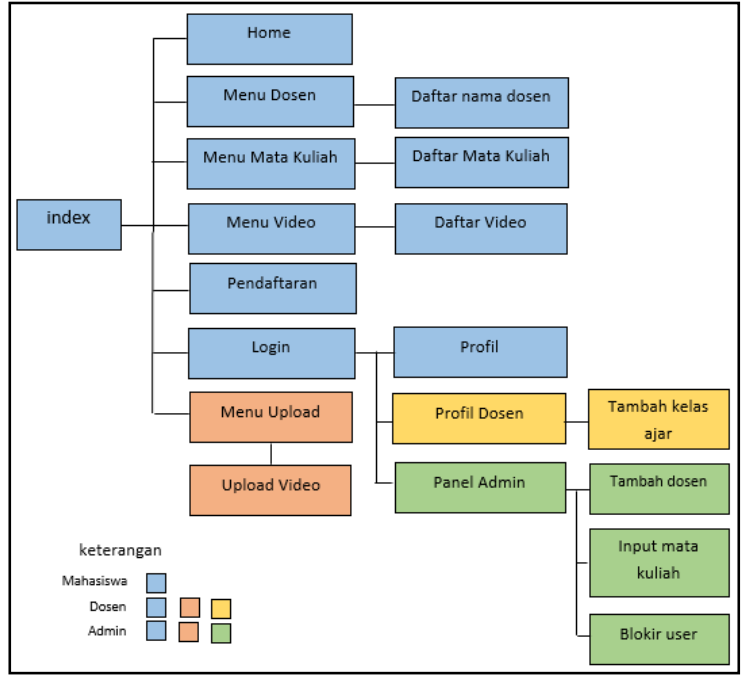

Gambar 3. Hirarki Program

\subsection{Implementasi Aplikasi}

Berikut hasil dari penerapan terhadap apliasi yang telah dikerjakan.

\section{a. Halaman Index (home)}

Halaman berikut merupakan halaman awal pada kondisi normal pada setiap pengguna

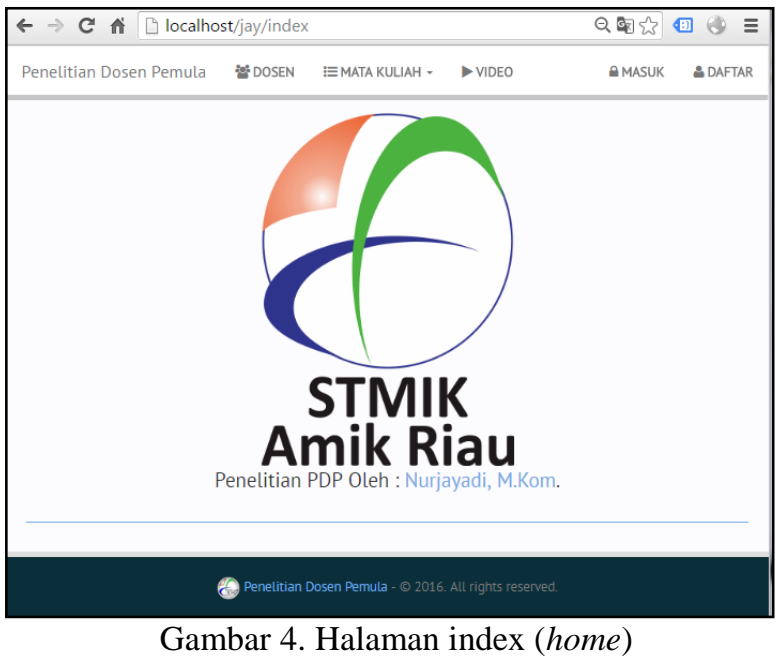

\section{b. Halaman Daftar}

Halaman ini dimana user yang belum terdaftar agar dapat melakukan pendaftaran akun melalui aplikasi.

\begin{tabular}{|c|c|c|c|c|c|c|}
\hline \multicolumn{2}{|c|}{ nelitian Dosen Pemula } & 형 DOSEN & :EMATA KULIAH - & DVIDEO & 9MASUK & $\therefore \mathrm{DAF}$ \\
\hline \multicolumn{7}{|c|}{ Daftar } \\
\hline a & Nurjayadi & & & & & \\
\hline$\square$ & \multicolumn{6}{|c|}{ nurjayadi@stmik-amik-riau.ac.id } \\
\hline 뭉 & \multicolumn{6}{|l|}{1027108101} \\
\hline a & \multicolumn{6}{|l|}{$\ldots . .}$. \\
\hline \multicolumn{7}{|c|}{ Angkatan: } \\
\hline \multicolumn{3}{|c|}{ Pilih Angkatan } & & & & r \\
\hline \multicolumn{3}{|c|}{ () wajib diisi } & & & Daftar & Reset: \\
\hline
\end{tabular}

Gambar 5. Halaman daftar

\section{c. Halaman matakuliah}

Halaman ini menampilkan video berdasar mata kuliah pilihan. 


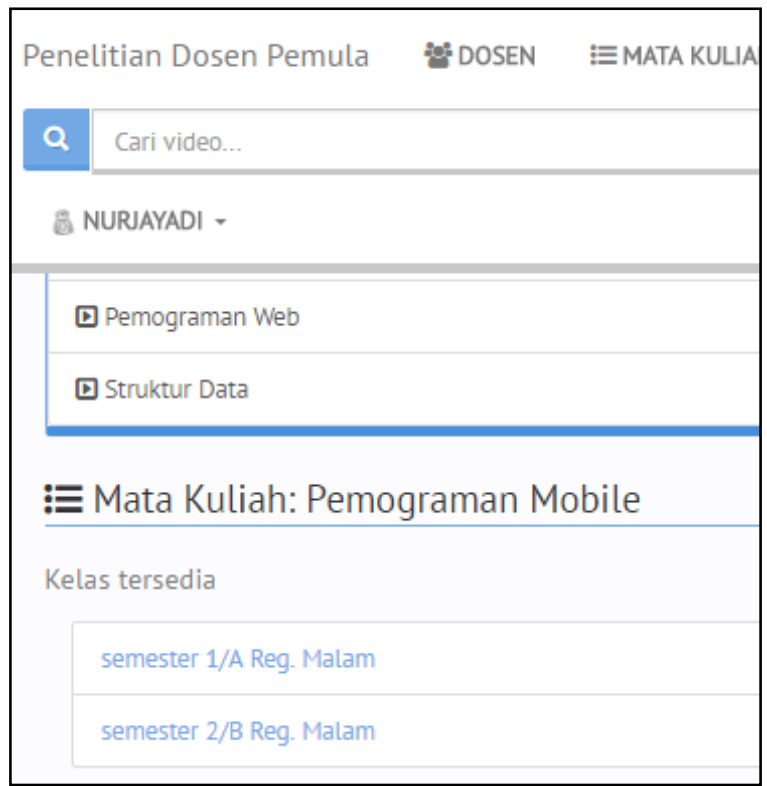

Gambar 6. Halaman mata kuliah

\section{d. Halaman Upload Video}

Form ini digunakan untuk melakukan upload video yang hanya dapat dilakukan oleh dosen ataupun admin

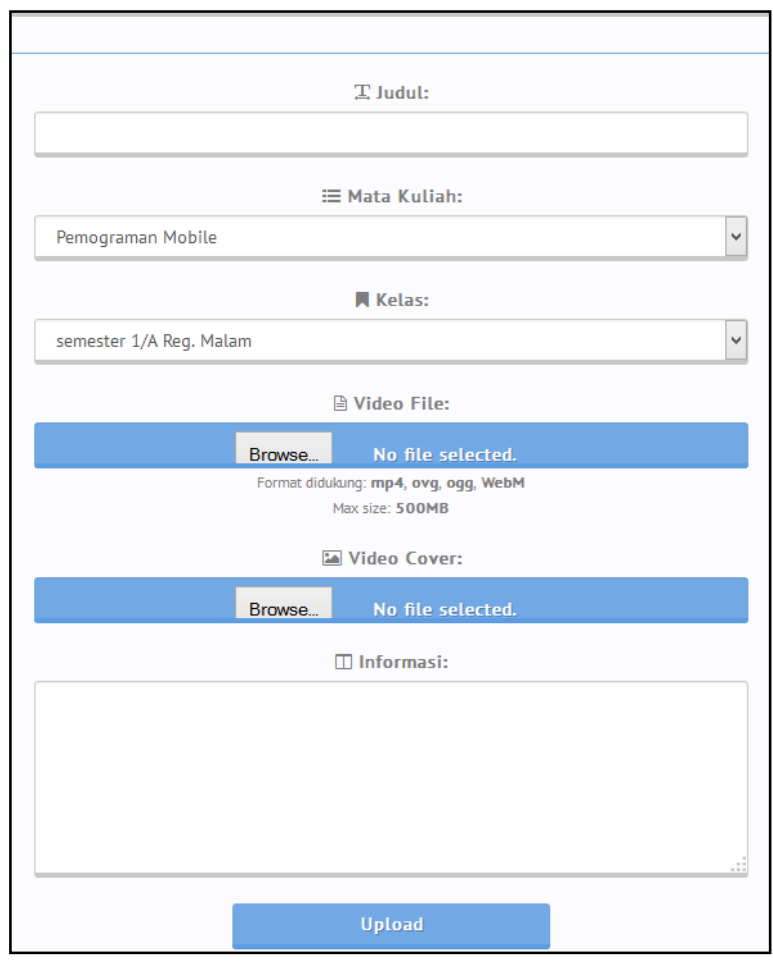

Gambar 7. Upload Video

\section{e. Halaman Kelola Aktifitas}

Halaman ini sebagai pengelolaan aktifitas meliputi upload video, kolom komentar pada video untuk berdiskusi, membuat favorit video dan akses download setiap video. Sementara penggunaan hak akses dalam sistem ini meliputi admin yang memiliki kewenangan dalam semua kegiatan sistem. dosen memiliki kewenangan melakukan upload/download video pembelajaran terkait mata kuliah yang diajar, Serta mahasiswa dapat melakukan interaksi tanya jawab pada kolom komentar video dan melakukan download video.

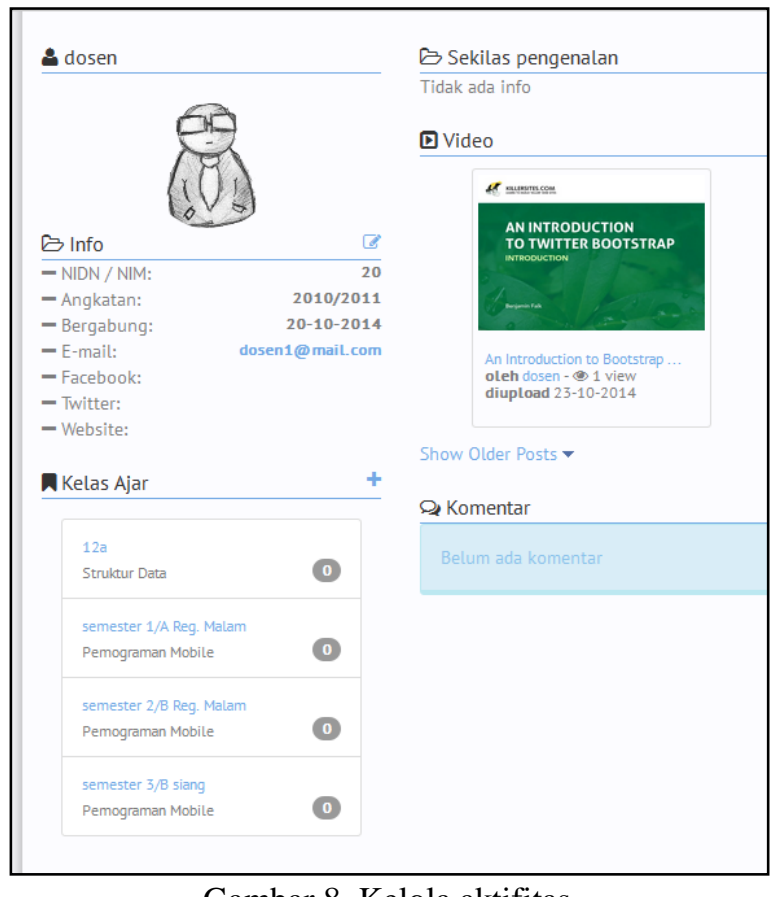

Gambar 8. Kelola aktifitas

Tujuan dari penelitian ini telah tercapai dengan membangun sebuah sistem pembelajaran di STMIK Amik Riau. Kegiatan belajar mengajar dapat lebih terbantu tanpa harus adanya pertemuan tatap muka langsung terutama pada matakuliah tertentu aplikasi ini dapat membantu mahasiswa dalam menyerap materi perkuliahan dengan mudah tanpa harus di dampingi dosen pengampu matakuliah. Dan pada kondisi ideal aplikasi video web ini berfungsi dengan baik, maka permasalahan perkuliahan terutama pada kelas praktikum menjadi solusi pada mahasiswa yang kesulitan mengikuti modul ajar yang dosen berikan. 


\subsection{Implementasi Accelarated Learning}

Dalam penerapan model accelarated learning dalam meningkatkan hasil belajar mahasiswa meliputi tiga konsep dasar, yaitu :

\section{a. Konsep belajar mengajar}

Pada dasarnya konsep belajar mengajar menuntut adanya interaksi dosen dan mahasiswa. Jadi antara konsep belajar dan mengajar harus berjalan secara beriringan. Dalam hal ini model accelarated learning diterapkan dengan pembelajaran secara online tanpa mengganggu perkuliahan di kelas. Dalam proses ini berjalan efektif karena latihan dan umpan balik diintegrasikan dengan materi yang diberikan di kelas sehingga memudahkan pemantauan dosen yang dalam pelaksanaan praktikum tidak di dampingi oleh dosen pengampu.

b. Strategi pembelajaran

Dalam strategi pembelajaran dosen mengarahkan mahasiswa menggunakan aplikasi yang dirancang, yaitu sebuah aplikasi web berbasis video. Dalam hal ini dosen dituntut mampu merancang strategi-startegi dan ide yang dapat menjadikan proses belajar berjalan dengan efektif dan efisien. Dalam hal ini kegiatan pembelajaran dapat berlangsung dengan baik apabila mahasiswa ikut berpartisipasi secara aktif di dalamnya.

c. Cara belajar mahasiswa.

Sistem berbasis web yang yang telah dibangun dapat menjadi pilihan lain bagi para dosen dalam penyampaian materi perkuliahan serta menjadi wadah pembelajaran bagi para mahasiswa ketika tidak lagi berada dalam proses belajar mengajar langsung di kelas. Sistem ini hanya dapat diakses oleh setiap dosen ataupun mahasiswa yang aktif pada matakuliah tertentu guna mengetahui bagaimana perkembangan pemahaman mahasiswa terhadap studi tertentu. Sedangkan seorang admin yang akan mengatur keseluruhan sistem agar dapat tetap berjalan dengan baik.

\subsection{Pengujian}

Pengujian dilakukan pada kelas praktikum yaitu di laboratorium komputer STMIK Amik Riau dengan melihat ketuntasan dalam mengerjakan modul praktikum.

Tabel 1. Perbandingan Nilai Ketuntasan

\begin{tabular}{|c|c|c|c|c|c|c|c|}
\hline \multirow{3}{*}{ NO } & \multirow{3}{*}{ NPM } & \multirow{3}{*}{ NILAI } & \multirow{2}{*}{\multicolumn{2}{|c|}{$\begin{array}{l}\text { MODUL PRAKTEK } \\
\text { KETUNTASAN }\end{array}$}} & \multirow{3}{*}{ NILAI } & \multirow{2}{*}{\multicolumn{2}{|c|}{$\begin{array}{c}\text { MATERI VIDEO WEB } \\
\text { KETUNTASAN }\end{array}$}} \\
\hline & & & & & & & \\
\hline & & & Tdk Tuntas & Tuntas & & Tdk Tuntas & Tuntas \\
\hline 1 & 1410031804008 & 90 & & $\checkmark$ & 90 & & $v$ \\
\hline 2 & 1410031804019 & 85 & & 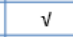 & 90 & & v \\
\hline 3 & 1410031804007 & 80 & $\checkmark$ & & 90 & & $\checkmark$ \\
\hline 4 & 1410031804023 & 80 & $v$ & & 90 & & $v$ \\
\hline 5 & 1410031804006 & 90 & & $v$ & 90 & & $v$ \\
\hline 6 & 1410031804005 & 80 & $v$ & & 90 & & v \\
\hline 7 & 1410031804014 & 85 & & v & 90 & & $v$ \\
\hline 8 & 1410031804011 & 90 & & $\checkmark$ & 90 & & v \\
\hline 9 & 1410031804009 & 90 & & v & 90 & & $\checkmark$ \\
\hline 10 & 1410031804022 & 80 & $\checkmark$ & & 90 & & $v$ \\
\hline 11 & 1410031804002 & 90 & & v & 90 & & $v$ \\
\hline 12 & 1410031804013 & 90 & & 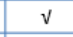 & 90 & & v \\
\hline 13 & 1410031804003 & 85 & & v & 90 & & $v$ \\
\hline \multirow[t]{3}{*}{14} & 1410031804012 & 85 & & $\checkmark$ & 90 & & $v$ \\
\hline & \multirow{2}{*}{\multicolumn{2}{|c|}{$\begin{array}{r}\text { Jumlah } \\
\text { Prosentasi (\%) }\end{array}$}} & 4 & 10 & & 0 & 14 \\
\hline & & & 28,57 & 71,43 & & 0,00 & 100,00 \\
\hline
\end{tabular}

Dari data yang ditampilkan pada Tabel 1 diperoleh dengan menerapkan web berbasis video dalam pelaksanaan praktikum, seluruh mahasiswa dapat mengerjakan modul yang diberikan dosen. Hal ini sangat berbeda jika masih menggunakan cara sebelumnya yaitu mengikuti modul praktikum nilai ketuntasan mahasiswa dalam mengerjakan tugas hanya diperoleh nilai $71,41 \%$ artinya ada $28,57 \%$ mahasiswa mengalami kesulitan dalam mengikuti modul yang diberikan.

\section{Kesimpulan}

Dalam membantu kegiatan belajar mengajar di kampus STMIK Amik Riau, aplikasi web berbasis video dapat digunakan dosen dan mahasiswa dalam melakukan proses pembelajaran diluar dari jadwal tatap muka yang telah ditetapkan. Sistem ini menyediakan upload video materi dan kolom komentar untuk tanya jawab langsung pada video untuk berdiskusi. Hak akses dalam sistem ini meliputi administrator, dosen dan mahasiswa. Sistem ini dapat menjadi penunjang materi di kelas sehingga prestasi hasil belajar mahasiswa meningkat. 


\section{Saran}

Pengembangan dirasa perlu terutama penerapan teknologi yang dapat diakses secara mobile dan cloud computing.

Peneliti mengucapkan terimakasih kepada kemenristek dikti melalui hibah penelitian dosen pemula, sehingga dalam penelitian tidak ada kendala dalam hal pembiayaan.

\section{Daftar Pustaka}

[1] Taufik, Husna. Penerapan Model Pembelajaran Accelarated Learning Model untuk Meningkatkan Hasil Belajar siswa Kelas X SMA Negeri 1 Dewantara pada Konsep Hukum Newton. Jurnal Pendidikan Almuslim. ISSN : 2338-7394. 2013.

[2] Azhar. Sistem Informasi Akuntansi : Konsep dan Pengembangan Berbasis Komputer. Bandung. Lingga Jaya. 2004

[3] Colin, Malcolm. Accelerated Learning For the 21 st century. London. 1997.

[4] Hamalik. Proses Belajar Mengajar. Jakarta. Bumi Aksara. 2008.

[5] Baharuddin, Wahyuni. Teori Belajar dan Pembelajaran. Yogyakarta: AR-Ruzz Media Group. 2007. 